\title{
Rosal de la Frontera (Huelva). Un fruto tardío de la utopía ilustrada
}

\author{
Manuel Antonio Cortés Ballesteros
}

Las ideas sobreviven a las rupturas históricas originando, en ocasiones, actitudes y hechos inexplicables bajo el prisma de los nuevos valores sociales o gustos estéticos. pero coincidentes en la causalidad y en la forma con otros anteriores de los cuales emanan. Mucho del arbitrismo del siglo XVII subyace en la política económica de los ilustrados. y bastantes programas del liberalismo decimonónico son hijos tardíos del Siglo de las Luces.

El estallido de la Revolución Francesa comprometió la tarea renovadora desarrollada bajo el reinado de Carlos III. A nivel de conciencia, durante los últimos años del XVIII, se asiste a la quiebra de la modernidad, al desencanto de quienes detentaron las «nuevas ideas». Algunos alarmados ante la dirección no deseada por la que discurren los cambios, olvidan las utopías regeneradoras de su juventud y se sitúan en el campo ideológico opuesto. Pero sus abandonados planes y sueños incuban en otras mentes que, pasado el tiempo y superada la reacción conservadora, acometerán acciones y proyectos cuya justificación ideológica heredaron.

Éste fue el caso que me ocupa. En marzo de 1820 Fernando VII se vio obligado a jurar la Constitución de Cádiz. Los sucesivos gobiernos del Trienio Liberal pondrán en marcha una política agraria y poblacional inspirada en la que Jovellanos y Olavide habían acometido medio siglo antes. En junio de 1822 varios decretos posibilitan el traspaso de los baldíos comunales a propiedad particular y abren nuevas expectativas de repoblación en términos municipales excesivamente extensos. Meses más tarde, en septiembre, el clérigo Gaspar García, diácono de la villa de Aroche (Huelva) en representación de 260 vecinos de dicha localidad, remite una instancia a la Diputación onubense, suplicando autorización para repoblar una antigua aldea, el Gallego, abandonada en 1642 en plena guerra hispano-lusa. 
Nuestros protagonistas se hallan imbuidos de las ideas fisiocráticas de los ilustrados. El citado eclesiástico, en carta al Gobernador de Huelva, dice:

«Si en todos tiempos, en todas naciones y bajo todo Gobierno ha sido mirada la agricultura como uno de los principales puntos de apoyo de toda sociedad constituida, tal vez en nuestra España no han faltado sabios que considerándola como exclusiva, la hayan presentado a la nación como el lírico manantial de toda riqueza pública y particular. El benemérito y sabio Jovellanos en la inmortal obra de Ley Agraria nos da un testimonio de esta verdad" $!$.

Conocedores de los aprietos financieros que lastran el Gobierno del moderado Martínez de la Rosa, añoran aquellos tiempos felices que «conoció la gloriosa e inmortal memoria del Sr. D. Carlos III en la nueva población de Sierra Morena». El Ldo. Valdés. consultado en 1838 sobre la utilidad de repoblar dicho lugar, expone en su informe: «En los cortos períodos que han respirado los españoles un ligero aire de libertad, han formado proyectos saludables, y entre ellos los de poblar varios terrenos incultos y en parte monstruosos». Todavía en 1844, en el acto de reparto de las tierras, un oficio dirigido a los nuevos colonos proclama: "Formáis una sociedad que su nombre y virtudes redundará en los extremos de la Monarquía»?

Todas las expresiones citadas podrían situarse en boca de cualquier político de 1767. Encierran la voluntad que gestó la repoblación de Sierra Morena. El deseo, en palabras del profesor Avilés Fernández, de hacer reai una concepción de la vida diferente de la que, de momento, se conocía. Un intento de concretar lo que podríamos definir como el horizonte utópico de la llustración ${ }^{3}$.

A lo largo del artículo veremos desfilar intenciones, actitudes y valores argüidos por los historiadores como causas o consecuencias de la empresa repobladora de Carlos III: desarrollo de la riqueza agrícola, ocupación de los espacios desiertos para asegurar los caminos, lucha contra el bandolerismo rural, proteccionismo forestal modificación en la estructura social de la propiedad, etc...

\footnotetext{
1 Archivo de la Diputación de Huelvâ, legajo 25, «Expediente sobre la repoblación de la Aldea del Gallego (1838)".

2 Archivo Municipal de Rosal de la Frontera, "Expediente primordial del repartimiento de terrenos a los vecinos de esta villa en los años de 1844, 1866 y 1868 ».

3 AVILÉS FERNÁNOEZ, Miguel, «Utopía y realidad: la descripción de la Sinapia, península en Tierra Austral, y las nuevas poblaciones en Andalucía", en las Nuevas Poblaciones de Carlos III en Sierra Morena y Andalucía. Actas del I Congreso Histórico. La Carolina, 1983.
} 
La misma oposición al proceso repoblador de los vecinos de Aroche, violenta en ocasiones, los defectos en el reparto de las parcelas, el racionalismo con que se diseña el urbanismo de la nueva población, el desencanto de los colonos que sucede al inicial estallido de ilusiones, y la actitud paternalista y protectora de la Diputación sobre la colonia permiten catalogar el asentamiento del Rosal como un fruto tardío de la ideología ilustrada.

La rapidez con que los braceros de Aroche responden a la iniciativa del Gobierno Liberal (apenas dos meses transcurren entre el Decreto regulador y la solicitud) induce a sospechar un antiguo estado de opinión favorable y quizás, a riesgo de equivocarme, algún intento repoblador fracasado durante el siglo anterior, al amparo de la política agraria del reinado carolino.

Motivaciones geográficas, históricas, demográficas y sociales avalan el éxito de la intentona, pese a las trabas de todo tipo que hallará en su camino.

Aroche, villa del reino hispalense fronteriza con Portugal, posee un término municipal de $708.6 \mathrm{Km}^{2}$ para un vecindario levemente superior a los dos mil habitantes. A finales del siglo XVIII el Concejo es propietario de unas siete mil fanegas de propios, a las que no afectaron las medidas desamortizadoras de 1770. La amplitud del término es esgrimida para justificar los asentamientos: "el inmenso término de Aroche más propio para una capital de las de primer orden, que para una villa que apenas en la actualidad cuenta 500 vecinos, está exigiendo no sólo una sino varias poblaciones en él». La mayor parte de estas tierras son incultas, ocupadas por monte bajo y encinares y de escasa calidad, aún cuando los partidarios del proceso repoblador hablen de "dilatadas y fértiles llanuras" o de "tierras fertilísimas, cruzada su campiña por dos abundantes riberas y varios arroyos».

En las primeras décadas del siglo xix se hallan vacías, sometidas a una explotación agropecuaria discontinua, con habituales rozas mediante el fuego, lo que origina la progresiva destrucción del arbolado. La lejanía del casco urbano, más de veinte leguas, dificulta el control de los abusos. Este argumento será esgrimido en coherencia con la política forestal de los gobiernos liberales.

Hasta el Seiscientos, la zona conoció un hábitat más disperso. Hay noticias de la existencia de una aldea cercana al lugar donde ahora pretende levantarse la nueva población, habitada por unos pocos vecinos cuya principal actividad debió ser la ganadería. El jesuita Pedro de León (en 1605) y Rodrigo Caro (en 1621) coincidieron en el carácter agraz de sus gentes 
y en el uso de un lenguaje fronterizo específico "como ratiños, ni sabian bien nuestra lengua, ni la de Portugal» ${ }^{4}$.

La rebelión del Duque de Braganza provocó el abandono de muchos lugares de las comarcas fronterizas extremeñas y andaluzas, retrayéndose sus moradores tras el escudo protector de las murallas de las villas mayores. La zona quedó como una tierra de nadie, vacía y yerma.

La indefinición jurídica de estos «desiertos» (hasta el siglo XIX no se acordarían sus primeros deslindes) propicia el contrabando, al que se dedicaban bastantes vecinos de Jabugo, Aroche y Encinasola. El aumento del fraude formará parte del ramillete de razones con las que el ayuntamiento de Aroche se opone a la empresa.

Sierras ariscas y solitarias son un lugar idóneo para el refugio de los malhechores. Escondite muchas veces, escenario las menos dado el poco comercio de sus caminos. La lucha contra el bandolerismo está en la mente de los políticos que apoyaron el asentamiento. "Cada colono sea un centinela contra los delincuentes" aconseja un bando. En 1858 dos carabineros destinados en Rosal fallecerán en violentos altercados con los contrabandistas.

Incendios, contrabando, desiertos, alimañas no explican por sí solas la terquedad con que se sostuvo la idea. Las causas profundas son de carácter demográfico y social. Entre 1808 y 1835 la villa de Aroche pasa de 550 a 660 vecinos. Este crecimiento no se vio acompañado de un paralelo aumento en la producción. Los datos denuncian un empobrecimiento continuo de los labradores. La competencia en la demanda de tierras elevó el precio de los arriendos, con la subsiguiente ruina de los pequeños arrendadores que engrosaron las filas de los jornaleros.

En 1835 la población agrícola de Aroche se compone de 58 propietarios, 212 labradores y 328 braceros. Sobre estos labradores un informe matiza que... «aunque éstos disfrutan de algún terreno, no pueden denominarse bajo ningún concepto en la clase propietaria, pues de ser una entidad pequeña, tienen sobre sí gravámenes cuyo censo anual casi equivale a su producto...». Es decir, eran pequeños parcelistas y arrendatarios que comparten el trabajo por cuenta propia con su contratación temporal como pegujaleros, con yuntas, completan su economía con la roturación de alguna suerte en los «propios» o en el «común», aunque, según las

\footnotetext{
1981.

4 LEÓN, PEDRo DE, Grandeza y miseria en Andalucía, Facultad de Teología. Granada,
} 
acusaciones que hacen al Ayuntamiento, los notables prefieran arrendar las sementeras y pastos a forasteros o portugueses.

El aumento demográfico coincide con una concentración de la propiedad que agudiza el hambre de tierras entre los desheredados de la comarca. En las solicitudes, los aspirantes a colonos confiesan «hallándose esta villa (Cortegana) muy poblada y no poder subsistir en ella a causa del poco término y muy escaso para labrar...», "ansiamos el cultivo de tierras». La venta de los propios en 1770 tuvo como raíz, según Gonzalo Anes, la gran demanda y la revalorización de las rentas agrarias. Así se explica la oposición que halló la medida entre los propietarios que controlaban los concejos, temerosos de un descenso en el valor de los arriendos y del encarecimiento de la mano de obra asalariada.

Conocemos la composición social de los 260 individuos que incoaron el expediente repoblador en 1822: 31 pequeños propietarios, 45 yunteros y 184 jornaleros. Estructura que explica la capacidad de convocatoria del clérigo Gaspar García y justifica la constancia con que el gobierno provincial reabre el proceso cada vez que el liberalismo asume el poder.

Sobreviven en el siglo xIX las teorías fisiocráticas sobre el aumento de la riqueza a través de una mejor distribución de la propiedad. Jovellanos en el Memorial ajustado de Ley Agraria expone que «la propiedad privada y la libertad de disponer aumentan y aseguran la riqueza particular y la pública». Para Olavide, el reparto de la tierra baldía, en plena propiedad o a censo, aumenta el número de labradores útiles con el resultado de una «infinita multiplicación de frutos y ganados, un comercio y una circulación activa». Se trata, pues, de transformar a los desheredados en ciudadanos productivos. mediante un acceso reglado a la propiedad de la tierra amortizada.

El mismo programa persiguen los actores de la empresa repobladora del Rosal. Partidarios y detractores coinciden en el substrato ideológico. «Déjese la población en su estado actual, repártanse sus terrenos como nuestro fraternal Gobierno manifiesta, establézcanse nuevas leyes para su cultivo y consideración, háganse propietarios a este grande y benemérito número de vecinos... y por el transcurso del tiempo se conseguirá todo poblarse... con ventajas de la mayor producción, mejores costumbres y aumento de brazos», argumentaba el Concejo de Aroche para justificar una negativa al asentamiento de la nueva población.

Reflejan estas palabras lo arraigado de las utopías ilustradas. En plena efervescencia social, se persigue la creación de una sociedad ideal, justa y equilibrada, en la que una nueva clase de pequeños propietarios, laboriosos y de buenas costumbres, vertebran un Estado disciplinado y regido por la Razón. Nada mejor para definir la utopía que el profesor Avilés des- 
cubrió en la «Descripción de la Sinapia, península en Tierra Austral», lugar donde el trabajo sería la única fuente de dignidad para el hombre y las relaciones sociales se organizarían de manera que «unos no revienten mientras otros, con desvergüenzas, se huelgan».

Jurídicamente, la fundación del Rosal tiene su origen en el Decreto de 29 de junio de 1822 sobre repoblación de términos extensos, facultad que el Gobierno concede a las restablecidas Diputaciones Provinciales.

Tras la instancia de don Gaspar García Soria, la Diputación, previo informe de Agustín Pereyra, se pronuncia favorablemente (6.05.1823).

Avatares políticos obligan al archivo del expediente. En octubre de 1823, al amparo de las bayonetas extranjeras, Fernando VII derogó toda la legislación del Trienio Liberal. El absolutismo de la Década Ominosa es recordado así en un documento del referido expediente: «Se hubiere ejecutado (el proyecto) si los tiempos y las circunstancias no hubieran tenido el cambio vergonzoso que en 1823 ahogó en la Península el generoso grito de libertad que había dado tres años antes. Se proscribió todo lo que pertenecía al sistema de la época Constitucional».

Seis meses después de la muerte del Deseado, marzo de 1834, el gobierno de Martínez de la Rosa reduce a propiedad particular los baldíos, realengos o de propios (medida ya tomada en 1813 y 1822). La decisión facilita la reapertura del proyecto del Rosal.

En junio, el nuevo Gobernador insta al Ayuntamiento de Aroche a entregar los antecedentes del caso, archivados en su secretaria, y en agosto se autoriza la nueva población.

Con el restablecimiento legal de las Diputaciones (1835), el procedimiento se agilizó. En abril el organismo provincial acuerda establecer en el término de Aroche tres nuevas poblaciones: en Valdosetella, en el Valle de las Peñas y en el sitio del Rosal. En febrero de 1838 se dictan las primeras instrucciones para el poblamiento y en diciembre se procede al deslinde de las dehesas con indicación expresa de los «propios» concedidos al Rosal.

Los primeros colonos seleccionados por una Junta de Población se instalan. En 1818 la aldea cuenta ya con 28 casas, dos molinos harineros y uno de cal. Seis años después las viviendas en uso son 62, 29 más se hallan en construcción y 90 solares esperan a futuros vecinos.

Las instrucciones otorgadas para la repoblación, inspiradas en el Fuero de las Nuevas Poblaciones de Sierra Morena, detallan el procedimiento jurídico, las normas urbanísticas, el proceso de selección de colonos, la fórmula para el reparto de tierras y el régimen de propiedad. 
El Ayuntamiento de Santa Bárbara, localidad vecina a quien se confía la ejecución del proyecto, y tres representantes de los colonos, formaron una Junta de Repoblación con funciones urbanísticas, selectivas y de asentamiento.

La colonia se abre a cualquier solicitante que reúna condiciones de moralidad y prudencia. Al admitido se le señala el terreno para levantar su casa. Al acabar la cimentación de la vivienda, se deslindan 50 fanegas (40 de tierra calma y 10 de arbolado) para la explotación directa por el nuevo colono. Esta parcela no podrá ser enajenada, ni en todo ni en parte en el plazo de diez años, bajo pena de decomiso, aunque sí se le autoriza a cambiarla por otra. Igualmente perderá su propiedad si abandona la vecindad del Rosal en los próximos diez años.

En 1844, tras ciertas protestas por irregularidades en los repartos, se aprobaron unas normas complementarias. El Ayuntamiento, ya constituido, deslindó de sus propios 200 suertes de pan llevar (de 10 a 20 fanegas de calidad), 200 cercados (de 5 a 6 fanegas en terrenos de buena calidad y a media legua del pueblo) y 200 huertos. Estas parcelas fueron adjudicadas mediante sucesivos sorteos.

El sobrante de los «propios» podía ser arrendado por el Ayuntamiento para hacer a sus gastos ordinarios. En dichos arriendos los colonos hallaban un complemento a su economía, ya que el canon a pagar era módico.

El uso de hierbas, rastrojos y bellotas permitía compaginar el trabajo agrícola con explotaciones ganaderas, atractivos suficientes para multiplicar el número de aspirantes. Si los primeros años de la colonia discurrieron entre la atonía y la escasez, se debió a la poca calidad de la tierra, a la nula capacidad inversora de los nuevos propietarios y a la violenta oposición de los vecinos de Aroche, defraudados por haber sido excluidos del proceso repoblador.

La roturación del monte bajo exigía un esfuerzo muscular y económico que muchos no deseaban o no podían realizar. La Administración Publica no prestó un apoyo económico como el recibido por los repobladores de Sierra Morena. Así que las suertes repartidas se vendían, a precios ínfimos, a otros colonos más laboriosos o afortunados o a forasteros sin vecindad en el término. La vigilancia administrativa, desbordada por los acontecimientos, fue incapaz de remediar estos vicios que socavaron la utopía social en que se gestó el Rosal.

La nueva población nace sin privilegios otorgados; lógico desde la esfera liberal, deseosa de acabar con todo tipo de tutela y proteccionismo. En marzo de 1835 la regente había abolido el fuero de población bajo el 
que se desarrollaron las colonias de Sierra Morena. Pero no conviene extremar la ingratitud. La Diputación onubense ejerció un celo vigilante y procuró incentivar a la nueva villa anulando las contribuciones que había de pagar (en 1845), y cediendo parte de los ingresos por rentas propias, paja, utensilios, culto y clero de las entidades locales provinciales para financiar al recién nacido municipio.

Únicamente Aroche desoirá la demanda como último gesto de la oposición que mantuvo ante un proyecto que le privó del 30 por ciento de su espacio económico y jurisdiccional.

Olavide había prevenido sobre el peligro que para las nuevas poblaciones iban a suponer los pueblos damnificados por el desgaje de sus territorios. La resistencia a la implantación de colonias se repitió una y otra vez. Espiel, Villaviciosa, La Rambla, Bailén, Sevilla o Villamartín son ejemplos de posturas antipobladoras, que si en la mayoría de las ocasiones optaron por la vía jurídica para la queja, en otras acudieron a la violencia, como Écija, para impedir el asentamiento de colonos.

Los labradores que controlan los Concejos ven en el proyecto un atentado a su predominio socio-económico. La mayor oferta de tierra, que convierte en propietario al labrantín, supone un descenso del precio de los arriendos y un encarecimiento del coste salarial, al reducirse la reserva de mano de obra en paro. La transformación de una parte de los propios en parcelas individuales, les priva asimismo de un lucrativo negocio especulativo.

Si la colonización se realiza con forasteros para obviar alguno de los efectos citados, será la masa de pegujaleros y yunteros sin tierra quienes se irriten. La reducción de los baldíos socaba sus posibilidades de subsistencia, al limitar y encarecer el arriendo de los mismos. Los nuevos colonos serán juzgados como intrusos y ladrones, y sobre ellos se vertirá la rabia vindicativa.

Ambos esquemas los veremos desarrollarse sucesivamente frente al proyecto del Rosal. El primer impulso repoblador partió de los braceros de Aroche. De inmediato, los hacendados, a través del Ayuntamiento, discuten la oportunidad de la idea con argumentos cuya motivación resulta obvia: El término, poco fructífero, se vería reducido y en su mayor parte controlado por forasteros absentistas. Los yunteros y pequeños labradores verían mermada su posibilidad de arrendar los propios, con el deterioro consiguiente de su nivel de vida. Como contrapartida ofrecen el repartir algunas suertes entre los desposeídos, al amparo del Decreto llustrado de 1770. El oportunismo de sus tesis es patente: conceden ahora lo que negaron antes. 
La polémica se agudizó con la publicación en la capital onubense de tres folletos aclaratorios de ambas posturas ${ }^{5}$.

Pero sería en 1838 cuando la atmósfera se enrareció. Los primeros colonos se han asentado ya, y la Junta de Población discrimina en la selección de aspirantes a los vecinos de Aroche. Ignoro la razón de la medida, tan injusta con quienes habían iniciado doce años antes todo el proyecto. Probablemente pretendería congraciarse con los «notables».

Ante la inutilidad de las vías política y jurídica, grupos de braceros recurren a la violencia física. En agosto destruyen las chozas de los primeros colonos y queman las sementeras. Los hechos se repetirán con la intención de desanimar a los aspirantes. El Juzgado de primera instancia de Aracena incoa un proceso, ordenando a la justicia de Santa Bárbara la creación de un cuerpo de Milicia Nacional, cuyos miembros, escogidos entre los colonos, presten ayuda a la Junta de Población. Idéntico encargo reciben los carabineros de Aroche.

La violencia reaparece tras el reparto de las suertes en 1839, con demoliciones de edificios, talas de árboles y quema de archivos. La responsabilidad "anarquista" de los desórdenes asusta a los conservadores, lo que facilitó la rápida represión de los mismos.

Aún en 1840, tras el Pronunciamiento de Espartero, el Ayuntamiento de Aroche se dirige a la recién creada Junta Directiva de la Provincia, a la espera de obtener la revocación de los acuerdos poblacionistas de la extinta Diputación. Sus esperanzas resultaron vanas. En abril de 1841 se da el paso decisivo para la repoblación.

Poco a poco la oposición mengua en acidez y virulencia. En 1844 sólo dos vecinos del nuevo pueblo proceden de Aroche. Entre 1856 y 1870, uno de cada cuatro forasteros que contraen matrimonio en la Parroquia de Rosal de la Frontera son naturales de la villa vecina ${ }^{6}$.

5 - «Noticia Histórica del proyecto de repoblación de la antigua aldea de Gallego que estuvo situada sobre la frontera de Portugal en el término de la villa de Aroche y refutación de los sofis más empleados por el Ayuntamiento de ésta para contrariar la ejecución de tan últil empresa», de José María Tenorio. Imp. № de Gálvez y Cia. Huelva-1837 (19 págs.).

— «efutación del opúsculo histórico sobre la utilidad de la repoblación de la aldea del Gallego, término de la villa de Aroche, con demostración de lo perjudicial de tal empresa". Anónimo. Imp. $\mathrm{N}^{\mathrm{a}}$ de Gálvez y Cia. Huelva-1837 (22 págs.).

- «Antídoto contra el veneno que destila el folleto titulado Refutación de la noticia histórica del proyecto de repoblación de la antigua aldea del Gallego" de José $\mathrm{M}^{\mathrm{a}}$ Tenorio. Imp. Na de Gálvez y Cia. Huelva-1837 (22 págs.).

6 Archivo Parroquial de Rosal de la Frontera. Libro de Desposorios y Velaciones I. 
El proyecto despertó grandes expectativas entre los braceros de la comarca. Las muchas solicitudes aconsejaron levantar algunas restricciones al asentamiento. En marzo de 1844, los solicitantes se elevan a 750 . En junio, los colonos ya instalados son noventa y uno. Proceden la mayoría de la zona norte (Encinasola e Higuera la Real) y de la Sierra de Aracena (Cortegana, Jabugo, Galaroza, Castaño y Valdelarco). La gran presencia de individuos procedentes de Encinasola (31\% sobre el total) y Cortegana $(18 \%)$ se explica por la cercanía de ambas villas al lugar repoblado. Extraña la ausencia de colonos procedentes de Aroche o de Santa Bárbara, lugares directamente ligados al proceso administrativo que alumbró la colonia 7 .

Los apellidos sugieren un alto grado de parentesco entre quienes proceden de la misma localidad; lógico habida cuenta del efecto reclutador que tiene la parentela y de la necesidad de ayuda recíproca no asalariada que exige la rotura del monte por parte de los labrantines.

Un $12,7 \%$ de los colonos ejercen oficios directamente relacionados con la actividad agraria (molinero, herrero, herrador, arriero...) o con la construcción (albañil. carpintero...); del resto, el 15\% eran labradores y el $71 \%$, jornaleros. Los testimonios se hacen eco de su escaso nivel económico. Sin duda el sector más sensible a la esperanza "de una nueva vida» es siempre el de los desheredados.

El carácter «pionero» de la población se manifiesta al analizar su estructura social. Es un grupo joven, formado por unidades familiares completas, de pocos miembros, con un elevado índice de masculinidad y débil presión de la población no activa.

La pirámide de edad se aproxima al ideal buscado por Olavide para los extranjeros que se reclutaran. La mitad son adultos en pleno vigor muscular y genético, aptos para los esfuerzos que han de soportar. Sólo una de cada cinco mujeres han de preocuparse por la crianza de algún bebé menor de dos años. Los inmigrantes que inician la aventura lo hacen en las mejores condiciones posibles: matrimonios aptos para el duro trabajo y la reproducción, pocos niños ya criados en buena parte, capaces algunos de ayudar a sus padres en la labor, y predominio de los varones ${ }^{8}$.

La nueva colonia crecerá a impulsos de una avalancha migratoria que se produjo entre 1841 y 1860. En la década de los sesenta el ritmo se

\footnotetext{
7 Moreno Alonso, Manuel, Colonización agraria y poblamiento en la Sierra de Huelva. El Rosal de la Frontera. Huelva, Ed. C.P., 1978.

8 GRÁFICA «Pirámide de edad».
} 
ralentizó; hasta 1895 no habrá un segundo acelerón demográfico. Farece como si en torno a 1855 el Rosal de Cristina hubiera alcanzado el «umbral máximo de población» ${ }^{9}$.

No hubo vacilaciones a la hora de fijar el emplazamiento de la nueva colonia. Basándose en razones estratégicas (centro geométrico del área a poblar cercano a la raya de Portugal), comerciales (en el camino que une Aracena con las ciudades lusas de Serpa y Moura permite un mejor control aduanero y el abastecimiento de los viajeros) y geográficos (con abundante agua y apta para la construcción) se señaló el área del Rosal como la más idónea para el asentamiento.

Se dictaron normas para la planificación racional del urbanismo. Los criterios del arquitecto encargado, D. Manuel de Zayas, están influenciados por conceptos neoclásicos, puestos ya en práctica en las Poblaciones de Sierra Morena: simplicidad, equilibrio y funcionalismo.

Se diseñaría un pueblo orientado a E. a O., de planta cuadrada y calles paralelas trazadas a cordel, alternando los cuarteles rectangulares con otros cuadrados de mayor dimensión. Su centro lo ocupa una plaza cuadrada, uno de cuyos lados se reserva para los edificios públicos.

La vía eje, de 17 varas, corre superpuesta al camino de Portugal. A la salida se sitúan el abrevadero del ganado y el cementerio. El lugar elegido para la iglesia era una pequeña colina al sur, en línea con las casas consistoriales, con intención de enriquecer la perspectiva superponiendo ambos planos de fachada.

Todo el programa rezuma reminiscencias del xvill: la unidad de composición, la funcionalidad rectilínea, la perspectiva que dé monumentalidad sin perder la simplicidad rural, el cuidado por la higiene, etc... No se trata de un mimetismo inconsciente, sino de un acto voluntario fundado en herencias ideológicas y culturales. La nueva estética (romanticismo), creada por la élite, tarda en desplazar a la precedente, especialmente en áreas alejadas de los centros emisores de poder y cultura.

La penuria en que discurrió la nueva colonia, impidió que se concretasen los planos de obra de D. Manuel de Zayas ${ }^{10}$. Las casas consistoriales y la iglesia parroquial de nítido sabor neoclásico y post barroco sólo pueden admirarse en los dibujos que realizó el arquitecto de la diputación provincial.

- GRÁFICA "Evolución de la población en Rosal de la Frontera durante el siglo XIX". GrÁFICA «Esquemas de las fachadas de la Iglesia y el Ayuntamiento del Rosal». 
Pero se respetó la regularidad y alineamiento primitivos, circunstancia que puede comprobarse paseando por las calles de la villa.

Rosal de la Frontera se alza como un monumento conmemorativo, erigido en honor de unas ideas capaces de sobrevivir a sus creadores y a su tiempo. Es el fruto de una hermosa utopía de cuyo fracaso hay que responsabilizar al egoísmo social, enemigo de la Razón y la Luz. 